\title{
A cartografia digital no território das escolas rurais do campo: potencializando espaços de comunicação entre escolas e formação continuada de professores
}

The digital cartography in the territory of rural rural schools: potentializing communication spaces between schools and teachers' continuing education

La cartografía digital en el territorio de las escuelas rurales del campo: potenciando los espacios de comunicación entre las escuelas y la formación continua del profesorado

Recebido: 04/02/2022 | Revisado: 09/02/2022 | Aceito: 19/02/2022 | Publicado: 01/03/2022

\author{
Marijane Rechia \\ ORCID: https://orcid.org/0000-0002-4719-6018 \\ Universidade Federal de Santa Maria, Brasil \\ E-mail: mjrechia@gmail.com \\ Helenise Sangoi Antunes \\ ORCID: https://orcid.org/0000-0001-6503-658X \\ Universidade Federal de Santa Maria, Brasil \\ E-mail: professora@helenise.com.br
}

\begin{abstract}
Resumo
Este artigo apresenta o processo de construção de uma Cartografia Digital das trinta Escolas Estaduais Rurais do Campo da $8^{\text {a }}$ Coordenadoria Regional de Educação (CRE), desenvolvida durante o curso de Mestrado em Educação no Programa de Pós-graduação em Educação (PPGE) da Universidade Federal de Santa Maria (UFSM), situada no Rio Grande do Sul (RS). Teve como objetivo geral compreender como a Cartografia Digital pode potencializar a formação continuada de professores, a comunicação e as relações entre as escolas. Ancorada em uma abordagem qualitativa, do tipo estudo de caso, as materialidades analisadas foram: entrevistas e questionários on-line, realizados com os professores alfabetizadores de duas escolas, dentre as trinta da $8^{\mathrm{a}}$ CRE. O referencial teórico baseou-se em Carvalho (2008); Menezes e Fernandes (2013); Callai (2004), entre outros. Resulta desse empreendimento de produção da Cartografia Digital: a ampliação da capacidade de interrelação e comunicação entre as diferentes Escolas Rurais do Campo; a possibilidade de construção de uma rede de formação continuada de professores, que contribua para processos de autorreconhecimento (entre escolas e docentes), bem como sua valorização; fortalecimento das memórias e histórias que estão no entorno das mesmas.
\end{abstract}

Palavras-chave: Escolas rurais do campo; Ensino; Cartografia digital; Formação continuada de professores.

\begin{abstract}
This article presents the process of building a Digital Cartography of the thirty Rural Rural State Schools of the 8th Regional Education Coordination (CRE), developed during the Master's Degree in Education in the Graduate Program in Education (PPGE) of the Federal University Santa Maria (UFSM), located in Rio Grande do Sul (RS). Its general objective was to understand how Digital Cartography can enhance the continuing education of teachers, communication, and relations between schools. Anchored in a qualitative approach, such as a case study, the materialities analyzed were: interviews and online questionnaires, conducted with literacy teachers from two schools, among the thirty from the 8th CRE. The theoretical framework was based on Carvalho (2008); Menezes and Fernandes (2013); Callai (2004), among others. The result of this Digital Cartography production enterprise is the expansion of the capacity for interrelation and communication between the different Rural Schools of the Countryside; the possibility of building a network of continuing education for teachers, which contributes to self-recognition processes (between schools and teachers), as well as their valorization; strengthening the memories and stories that surround them.
\end{abstract}

Keywords: Rural rural schools; Teaching; Digital cartography; Continuing education for teachers.

\section{Resumen}

Este artículo presenta el proceso de construcción de una Cartografía Digital de las treinta Escuelas Estatales Rurales de la $8^{\mathrm{a}}$ Coordinadora Regional de Educación (CRE), desarrollado durante la Maestría en Educación del Programa de Postgrado en Educación (PPGE) de la Universidad Federal de Santa María (UFSM), ubicada en Rio Grande do Sul (RS). Tenía como objetivo general entender cómo la Cartografía Digital puede mejorar la formación continua de los profesores, la comunicación y las relaciones entre las escuelas. Anclado en un enfoque cualitativo, tipo estudio de caso, las materialidades analizadas fueron: entrevistas y cuestionarios en línea, realizados a profesores de alfabetización de dos escuelas, entre las treinta del $8^{\circ} \mathrm{CRE}$. El marco teórico se basó en Carvalho (2008); Menezes y Fernandes (2013); 
Callai (2004), entre otros. El resultado de este emprendimiento de producción de Cartografía Digital es: la ampliación de la capacidad de interrelación y comunicación entre las distintas Escuelas Rurales del Campo; la posibilidad de construir una red de formación continua de docentes, que contribuya a procesos de auto reconocimiento (entre escuelas y docentes), así como su valorización; el fortalecimiento de las memorias e historias que las rodean.

Palabras clave: Escuelas rurales en el campo; Enseñanza; Cartografía digital; Formación continua del profesorado.

\section{Introdução}

O presente estudo apresenta o processo de construção de uma Cartografia Digital das trinta Escolas Estaduais Rurais do Campo da $8^{\text {a }}$ Coordenadoria Regional de Educação (CRE), desenvolvida durante o curso de Mestrado em Educação no Programa de Pós-graduação em Educação (PPGE) da Universidade Federal de Santa Maria (UFSM), situada no Rio Grande do Sul (RS). Tem como objetivo geral compreender como a Cartografia Digital pode potencializar a formação continuada de professores, a comunicação e as relações entre as escolas.

Conforme aponta a Resolução $\mathrm{n}^{\mathrm{o}}$ 2, de 28 de abril de 2008, a qual estabelece diretrizes complementares, normas e princípios para o desenvolvimento de políticas públicas de atendimento da Educação Básica do Campo esta, trata-se:

Art. $1^{\circ}$ A Educação do Campo compreende a Educação Básica em suas etapas de Educação Infantil, Ensino Fundamental, Ensino Médio e Educação Profissional Técnica de nível médio integrada com o Ensino Médio e destinase ao atendimento às populações rurais em suas mais variadas formas de produção da vida - agricultores familiares, extrativistas, pescadores artesanais, ribeirinhos, assentados e acampados da Reforma Agrária, quilombolas, caiçaras, indígenas e outros (Brasil, 2008, p. 01).

As Escolas Rurais do Campo foram historicamente desqualificadas por uma trajetória de tentativas políticas em manter o povo das comunidades rurais do campo afastados das cidades e, ao mesmo tempo, trabalhando para garantir a produção de alimentos. Essas escolas sempre foram pequenas e espalhadas por várias localidades rurais. De modo geral, o professor ia até a escola e algumas vezes, devido à distância, era obrigado a se hospedar na casa de algum aluno. Com a pretensão de alcançar uma maior qualidade, surgiu a nucleação e a maioria dessas pequenas escolas acabaram sendo fechadas. A partir disso, as crianças começaram se deslocar até a escola mais próxima, obrigando os alunos a um convívio com colegas e professores moradores das cidades. Isso fez com que os professores não precisassem mais viajar para localidades com escolas em condições precárias. Houve a aproximação da indústria, frigoríficos e prestadores de serviços e, portanto, a agricultura deixou de ser exclusividade para o trabalho nessas comunidades.

Com essa aproximação do rural, do campo e urbano, percebe-se que há certa dúvida sobre as terminologias rural e do campo, não havendo uma definição exata em termos de compreensão coletiva para essas escolas - elas localizam-se entre o campo, o rural e o urbano. Para Figueiredo e Silva (2020),

A educação do campo é também um tipo de educação que, diferente da educação rural, valoriza a realidade campesina e o sujeito do campo em sua integralidade. Existe a valorização da identidade do camponês, do território que ele ocupa e de seu modo de vida e, por isso, um caráter ético-político do fazer educativo (p. 10).

De modo geral, a educação do campo está muito forte nos assentamentos, nas lutas coletivas pela educação do campo e pela permanência no trabalho com a terra. De acordo com Kolling et al., (2002, p. 18), uma das particularidades do “[...]movimento por uma educação do campo é a luta do povo do campo por políticas públicas que garantam o seu direito à educação". Há uma diversidade que compõe os povos do campo e por isso, torna-se importante respeitar o "direito de ser educado no lugar onde vive e também a uma educação pensada desde o seu lugar e com a sua participação, vinculada à sua cultura e às suas necessidades humanas e sociais" (Gelocha \& Antunes, 2021, p. 12).

No entanto, apesar de leis e decretos disponíveis, as escolas desses contextos vêm sendo enfraquecidas ao longo da 
história, principalmente em pequenas localidades marcadas pelo trabalho manual e sem necessidades de muitos conhecimentos científicos para auxiliar na vida desses sujeitos. Para Arroyo (1999, p. 32) "[...]essa visão utilitarista sempre justificou a escola rural pobre, os conteúdos primaríssimos, a escolinha das primeiras letras".

Para mudar o rumo dessa história me inspiro em Amiguinho (2005) para sinalizar a necessidade de tirar do papel discussões acerca do tema, colocando em prática ideias que aprimorem o que existe, produzindo outras coisas que auxiliem no transformar das realidades. Para Callai $(2004$, p. 3) "a pesquisa na escola se apresenta como possibilidade de busca/investigação e produção de conhecimento". Conhecimento fundamental para mobilizar e incentivar diferentes movimentos e organizações na busca da expansão necessária para a valorização da educação do campo. (Medeiros, 2012)

Levando isso em conta, a partir de uma pesquisa guarda-chuva oriunda do Grupo de Estudos e Pesquisas sobre Formação Inicial, Continuada e Alfabetização (GEPFICA/UFSM), intitulada "Cartografias da Educação Básica em Escolas Rurais: perspectivas para a formação e atuação de professores da região central do Rio Grande do Sul" (CEBER), que foi desenvolvida entre os anos de 2013 e 2018, é que me aproximo do desenvolvimento de uma cartografia digital intitulada: "A Cartografia Digital das Escolas Rurais do Campo" (CDERC).

Com base nesse processo de construção, a seguir aponto o viés metodológico do estudo cartográfico, seguido da cartografia digital que foi elaborada a partir das 30 Escolas Estaduais Rurais do Campo da $8^{\mathrm{a}}$ CRE.

\section{Metodologia}

A cartografia tem sido hoje utilizada nas mais diversas áreas do conhecimento. Para Carvalho (2008, p. 02), a existência da cartografia e "os conhecimentos cartográficos são imprescindíveis e, até mesmo, vitais, para a humanidade", pois, para o autor, independentemente do tipo de abordagem, elas [...]mostram a utilização das representações cartográficas em diferentes épocas e lugares do mundo por diferentes povos" (Carvalho, 2008, p. 02). Essas representações iniciaram pelo "desejo de representar o espaço e, para isso, fizeram uso dos recursos de que dispunham, como a argila, o papiro, as peles de animais ou as inscrições rupestres" (Carvalho, 2008, p. 03).

O desenvolvimento dessas habilidades, tem despertado a curiosidade e conhecimento científico com a utilização de linguagens que possam mostrar aspectos que dizem respeito às paisagens e também vivências dos povos, suas práticas que se dão no ambiente social, demarcação do espaço, localização de pontos, bem como demais traçados que digam respeito a rotas particulares (Carvalho, 2008). Devido a isso, a cartografia é conhecida como responsável pela elaboração e estudo dos mapas e representações cartográficas em geral, incluindo plantas, croquis e cartas gráficas.

Para Menezes e Fernandes (2013, p. 13) o intento com a ação de detalhar e também aperfeiçoar "feições representadas sempre esteve presente nas pesquisas cartográficas, mas, no entanto, a pesquisa científica e a preocupação epistemológica foram postergadas". Ao contrário, atualmente, a arte de cartografar avança em várias direções, possibilitando sua utilização, em todas as áreas de conhecimento.

Dessa forma, "a cartografia engloba, portanto, todas as atividades que vão do levantamento de campo ou da pesquisa bibliográfica até a impressão definitiva e a publicação do mapa elaborado" (Menezes \& Fernandes, 2013, p. 18). Esse leque de opções cartográficas tem atraído a pesquisa e a criatividade, mas "é importante considerar que aceitar essas formas de representação do espaço e qualificá-las de Cartografia é algo mais recente" (Carvalho, 2008 p. 04). Essa evolução iniciou pela relevância de representar espaços de vivência "para a própria sobrevivência dos grupos humanos. Especialmente, das populações nômades, para as quais o desenho dos itinerários e dos pontos de interesse a eles associados era vital" (Carvalho, 2008 p. 03 ). Devido a isso, a arte de cartografar nos permite ler o mundo, o lugar, o espaço e:

Fazer a leitura da paisagem, é portanto, uma possibilidade para que seja lida a realidade, percebendo a história, o 
movimento, a mobilidade territorial, a seletividade espacial que é resultado social. Através da cultura, muitas vezes territorializada no espaço de uma ou de outra forma, pode se perceber laços que os indivíduos tramam entre si, as formas de ação em relação ao ambiente, à natureza. Reconhecer a cultura local significa perceber, a história do lugar, as origens das pessoas, as verdades e os valores que pautam as relações entre elas (Callai, 2004, p. 05).

Diante disso, nasce a intenção de pesquisar sobre a utilização da Cartografia Digital. Uma investigação para descobrir o que, além do histórico e informações básicas, seria possível inserir na cartografia digital para contribuir com a formação continuada de professores, a comunicação e as relações entre as escolas. Para Nóvoa (2009, p. 23) é urgente a "construção de redes de trabalho colectivo que sejam o suporte de práticas de formação baseadas na partilha e no diálogo profissional”. Para Santos p. 176) “[...]a rede é também social e política, pelas pessoas, mensagens, valores que a frequentam.

Nesse sentido, a Cartografia Digital será o elo de comunicação para os professores dessas escolas, visando compreender como a cartografia digital poderá potencializar a formação continuada de professores, a comunicação e as relações entre as escolas rurais do campo de abrangência da $8^{\circ} \mathrm{CRE}$.

Ancorada em uma abordagem qualitativa, na modalidade estudo de caso, teve como a produção de informações, os resultados de entrevistas e narrativas que foram realizadas com os professores alfabetizadores de duas entre as 30 Escolas Estaduais Rurais do Campo, participantes do projeto CEBER.

Com essa perspectiva, a cartografia digital, deixa de ser apenas a representação de um espaço geográfico, para abrir espaços que possam divulgar uma realidade que é comum as escolas. Desafios enfrentados diariamente: acesso, transporte, formação continuada de professores, infraestrutura, comunicação, relações, entre outros.

Amiguinho (2008, p. 28) nos diz que:

[...] os professores são desafiados, isolados nas suas classes, a cooperarem e a colaborarem para fazer face à heterogeneidade crescente dos alunos, das solicitações das famílias, à diversidade de formas de aprender concorrentes com a forma escolar, no seio de outras instituições educativas de que a escola continua a alhear-se. Isto é, são colocados na situação de preservarem simbolicamente a natureza da escola, e o exercício profissional individualizado que a caracteriza, ao mesmo tempo que são impelidos a interagir para suplantarem as dificuldades daquele exercício e as novas exigências profissionais, onde os modos de trabalho dominantes também se têm revelado completamente incapazes.

Essa incapacidade aumenta com o distanciamento entre o que é vivenciado fora e dentro da escola, pois a maioria dos professores são formados com práticas em escolas urbanas e, quando vão atuar nas escolas rurais, sentem a dificuldade da inserção nesse novo contexto, gerando conflitos e tensões sobre as perspectivas, valores e peculiaridades no convívio social.

A partir da explanação do viés metodológico da presente pesquisa, a seguir mobilizo o compartilhamento do processo de construção cartográfica.

\section{Resultados e Discussão}

Os espaços quando mapeados, estabelecem uma conexão entre as escolas, tornando o isolamento, até então, existente, em uma proposta de rede colaborativa e de acesso público. Durante o processo de participação no CEBER, tive a possibilidade de entrar em contato com muitas das Escolas Rurais participantes do projeto. A partir disso, comecei o mapeamento das suas localizações no cenário estadual.

No processo de construção da cartografia os endereços foram incluídos no Google Maps, utilizando como referência, a latitude e longitude, correspondente a cada endereço das Escolas Rurais pesquisadas. O girassol, um dos símbolos das Escolas do Campo, foi utilizado para representá-las geograficamente, conforme apresenta a Figura 1. Ao clicar sobre cada girassol, é possível abrir uma janela contendo uma série de informações básicas da escola, como, por exemplo: município, registros 
fotográficos, o número do telefone e e-mail.

Figura 1 - Mapeamento das trinta escolas no Google Maps.

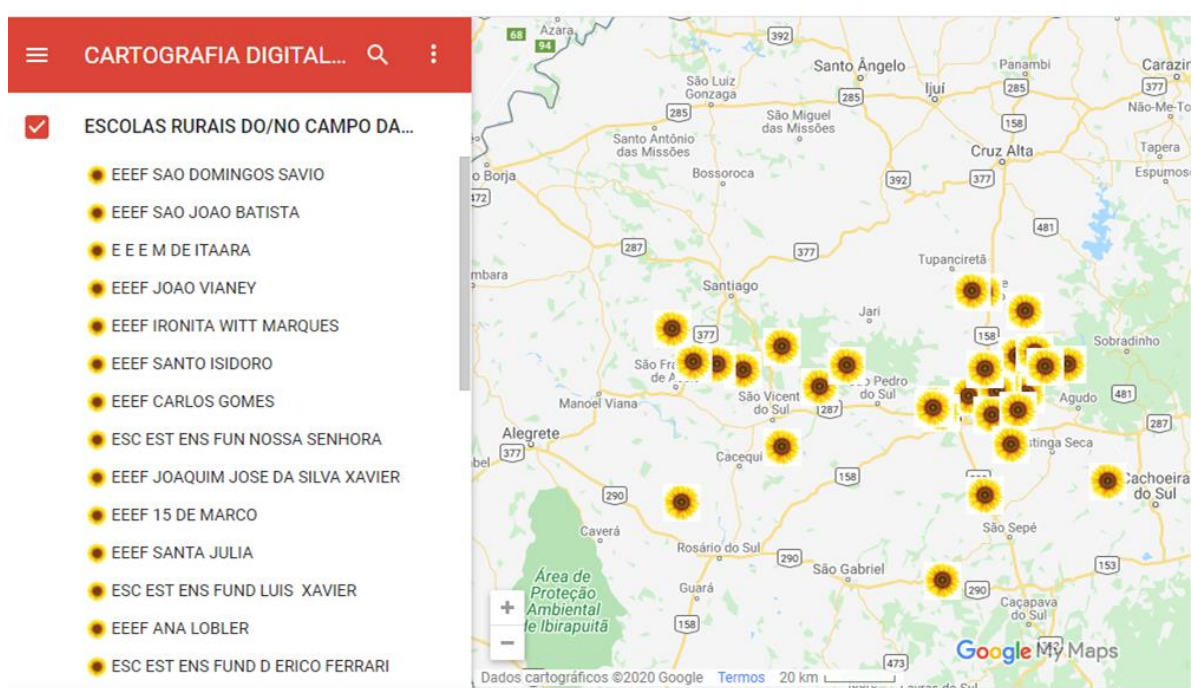

Fonte: Arquivo autores. Print Screen SysRq.https://sites.google.com/view/cartografiadigital/p\%C3\%A1gina-inicial (Rechia, 2019).

A representação cartográfica das trinta escolas, possibilita a elaboração e compartilhamento de um arquivo digital, de acesso público, que pode vir a incentivar novas pesquisas e políticas públicas que valorizem "o papel institucional das pequenas estruturas escolares na hipotética construção de uma nova ruralidade" (Amiguinho, 2008, p. 24).

Essa possibilidade da cartografia digital surge contribuindo para a preservação do histórico das escolas. Sabendo do histórico de desconexão entre o andamento dessas escolas, tendo em vista seu distanciamento e, muitas vezes, a falta de comunicação, a cartografia digital favorece a memória coletiva que caracteriza a história local das comunidades, das escolas investigadas. Ao longo do processo de desenvolvimento dessa investigação, cinco, entre as trinta escolas mapeadas, foram fechadas. Contudo, estão presentes na cartografia digital, como uma forma de preservação de memórias e de uma história dedicada à educação, que por meio do:

olhar espacial, nos permite fazer a leitura do território marcado pela história da vida das pessoas que ali vivem e tornase fundamental para que não se fique apenas nas descrições do aparente, olhar e conseguir perceber o que está por detrás dessa aparência. Reconhecer os interesses envolvidos, as motivações, as lutas sociais, a capacidade de articulação das pessoas do lugar, significa ler para além da paisagem (Callai, 2004, p. 05).

Apesar do importante passo para evidenciar a existência das Escolas Rurais do Campo da $8^{\mathrm{a}} \mathrm{CRE}$, o desenvolvimento de um mapa com a localização das escolas fez nascer novas perspectivas para ampliar a sua relevância. Dessa forma, os novos itens, conteúdos e atividades fortaleceram as escolas como a identidade das suas comunidades. Isso é importante, pois "reconhecer a cultura local significa perceber, a história do lugar, as origens das pessoas, as verdades e os valores que pautam as relações entre elas" (Callai, 2004, p. 05).

Mas como seria possível aproximar esses professores, potencializar a formação continuada, ampliar a rede de informações e ao mesmo tempo manter o mapeamento já realizado no Google Maps? Para responder a esta questão foram iniciadas novas pesquisas sobre ferramentas que atendessem a essas expectativas. O Google site, por ter a compatibilidade com o Google Maps e também com o Google Hangouts, foi escolhido como um ótimo espaço para divulgar conteúdos, projetos e práticas, bem como, oportunizar a comunicação entre as escolas, conforme Figura 2. 
Figura 2 - Print da página inicial do site da Cartografia Digital das Escolas Rurais do Campo CDERC.

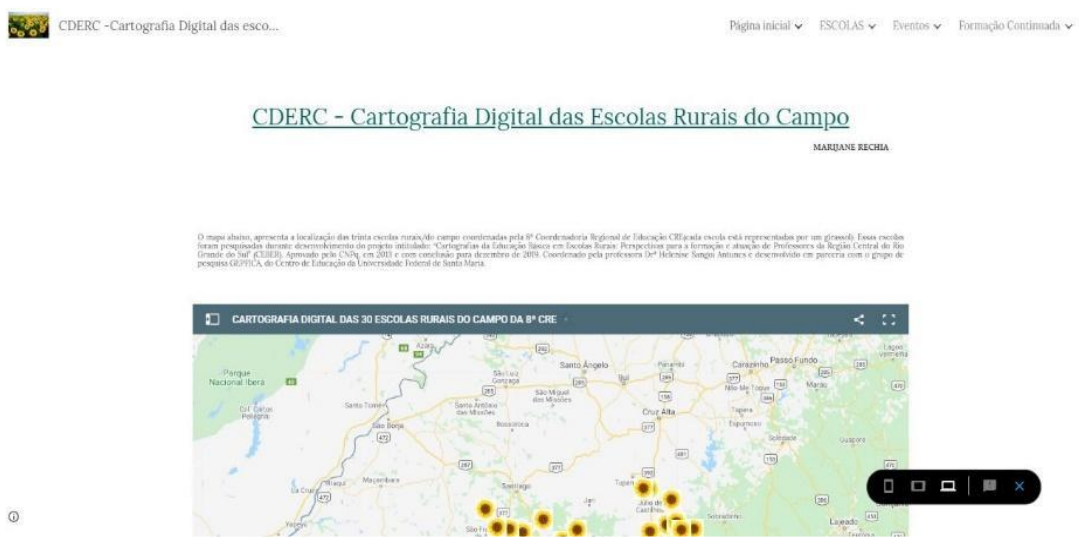

Fonte: Arquivo autores. Print Screen SysRq. https://sites.google.com/view/cartografiadigital/p\%C3\%A1gina-inicial (Rechia, 2019).

Sabendo disso, após a construção da Cartografia Digital, esta foi submetida a uma avalição por parte de professores e gestores das duas escolas participantes da pesquisa.

Conforme sinaliza Monmonier (1982, p. 01) a "cartografia se refere à ciência e arte e é o estudo dos métodos de mapeamento e comunicação por meio de mapas". Mas como viabilizar a comunicação entre as escolas? Para a autora, a Cartografia Digital tem, entre seus objetivos, a comunicação e a visão total de uma determinada situação, que possam através das informações coletadas, auxiliar em uma tomada de decisão que envolva o contexto pesquisado.

$\mathrm{O}$ acesso às informações, a interlocução e troca de saberes entre as escolas é uma ferramenta importante na pesquisa com vistas a compartilhar experiências que poderão contribuir para a reflexão e novos pontos de vista sobre os mais diversos assuntos que estão atrelados ao campo da formação. A compreensão sobre a nova forma de se comunicar e suas perspectivas com relação aos grupos sociais e suas propostas por meio da comunicação digital, portanto, favorecem a "conversação em rede e suas possíveis contribuições" (Recuero, 2012, p.19). Nesse processo, visualizou-se o quanto a Cartografia Digital seria importante para as escolas e os docentes:

[...]a gente sofre, correndo, separadamente pelos mesmos problemas. Então, com esse projeto da cartografia vai ser muito legal pra nós. Precisamos nos unir, e pela distância, fica difícil, então, com essa ferramenta vai facilitar, agilizar muito a nossa comunicação e vamos poder dialogar com todas as escolas, vamos poder trabalhar juntos, unidos (Entrevista Narrativa - Diretor(a) de uma das escolas).

De acordo com o diretor, a Cartografia Digital poderá unir as escolas na tomada de decisões, promovendo o diálogo e o trabalho coletivo. Para Nóvoa (2009, p. 42) é urgente "reforçar as comunidades de prática, isto é, um espaço conceptual construído por grupos de educadores comprometidos com a pesquisa e a inovação, no qual se discutem ideias sobre o ensino e aprendizagem e se elaboram perspectivas comuns". Para isso, os gestores e docentes colaboradores dessa pesquisa, fizeram suas avaliações quanto a utilização da Cartografia Digital. Receberam um questionário on-line contendo uma pergunta objetiva e duas dissertativas. Não houve identificação dos participantes e houve 100\% de participação.

No Print Screen anexo abaixo (Figura 3), verifica-se que conforme as respostas da pergunta objetiva $100 \%$ dos colaboradores responderam 'sim' à questão sobre a contribuição da CDERC como dispositivo potencializador na formação continuada de professores. 
Figura 3 - Gráfico de respostas da pergunta objetiva questionário on-line.

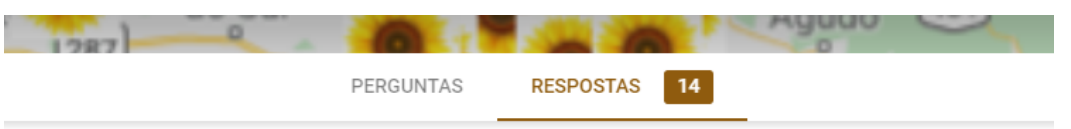

Acesse o site da Cartografia Digital das escolas rurais do campo, no link abaixo, e de sua opinião se a mesma poderá contribuir ou não como dispositivo potencializador na formação continuada de professores: https://sites.google.com/view/cartografiadigital/página-inicial

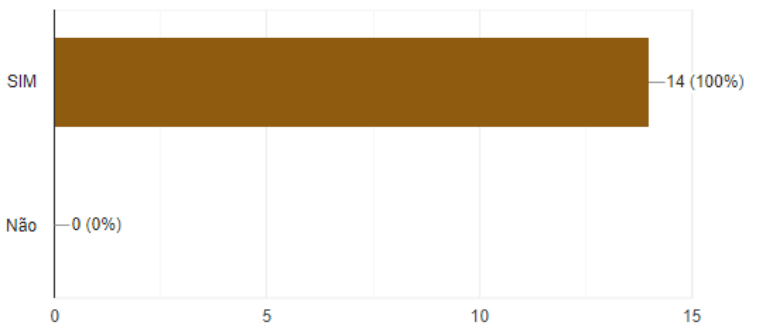

Fonte: Arquivo autoras. Print Screen SysRq. Respostas questionário formulário Google (Rechia, 2019).

A avaliação foi realizada com acesso de todos ao link disponibilizado junto ao questionário on-line, com o link para acesso e perguntas com a avaliação sobre o conteúdo disponibilizado na CDERC. A CDERC foi acessada pelo menos uma vez, por todos os sujeitos colaboradores da pesquisa.

Em relação às percepções, dentro do espaço escolar e com os pares, foram solicitadas sugestões aos colaboradores da pesquisa. Sugestões sobre o que seria interessante de ser adicionado à Cartografia Digital, para que ela pudesse contribuir para as demandas de formação continuada dos docentes da sua escola. Como resultado, foram sugeridos os seguintes temas: A criação de um espaço para socialização de trabalhos, eventos, dúvidas e outras demandas pertinentes às escolas do campo; Além do levantamento das escolas rurais, deveria incorporar formações sobre a escola do campo. Essas poderiam ser paralelas a elaboração da cartografia; Formação presencial do curso; Os desafios inerentes à realidade geográfica dos alunos-Distância; Que apresentasse estratégias que demandem a realidade da nossa escola; Troca de experiências entre professores que atuam nas escolas do campo; Práticas das escolas, para que possam ser partilhadas.

As sugestões foram acolhidas e inseridas na Cartografia Digital, atendendo as solicitações e demandas elencadas nas respostas ao questionário on-line. Outras avaliações foram sendo realizadas no decorrer da pesquisa. Em uma delas, emergiu um espaço para descrever como eles construiriam uma Cartografia Digital, diferente do projeto apresentado, com vistas a construir contribuições para melhorar sua formação continuada como docente. As respostas obtidas a partir da pergunta, envolvendo dez colaboradores da pesquisa, foram as seguintes:

Não penso em uma cartografia diferente, mas, com mais elementos interativos (Docente A).

Não faria diferente, apenas acrescentaria encontros presenciais formativos (Docente B).

Faria um curso para adaptar a realidade da localidade, pois até esta data, tenho conhecimento superficial do assunto (Docente $C$ ).

Um mapeamento das realidades da zona rural onde moram os alunos; que a formação contemplasse e oportunizasse criar instrumentos de troca de experiências de outras realidades; como enfrentam os desafios das escolas de campo (Docente D). 
A realidade cultural, uma ênfase maior à cultura escolar do campo. Mapeando as realidades, de onde advêm os educandos (Docente E).

Mapeamento sócio antropológico das realidades, partilha de dados dos desafios enfrentados pelos professores, que atuam no meio rural (Docente F).

Caracterizar as escolas que fazem parte. Materiais com atividades diversas que possam ajudar na formação dos professores e no dia a dia de sala de aula (Docente $G$ ).

A profissão do professor é um desafio constante e permanente, para o qual o educador leva em conta o saber e a curiosidade dos alunos, através de estudos do meio, trabalhos em equipes (Docente H).

Eu não acrescentaria, praticamente nada. Mas, continuaria desenvolvendo um trabalho voltado ao desenvolvimento das potencialidades dos alunos, levando os mesmos a compreender, criticamente, o mundo em que vivem (Gestor A).

O avanço da comunicação e o acelerado mundo tecnológico diminuíram as distâncias. Acessamos muitas coisas, instantaneamente, para nos localizarmos ou até mesmo, para chegarmos a algum lugar. Então, a cartografia apresentada é muito boa, clara e objetiva. Também gostei muito dos girassóis. Os produtos cartográficos, quando são usados nas aulas, proporcionam uma aula dinâmica e com várias discussões, facilitando aos alunos a entenderem o espaço geográfico (Gestor B).

As avaliações, foram acontecendo em estágios distintos de elaboração da CDERC. Estas últimas aconteceram quando novos conteúdos foram agregados a Cartografia Digital. De acordo com Menezes e Fernandes (2013), o conteúdo de uma representação cartográfica será expressivo na medida em que a sua linguagem mostre, com clareza, a mensagem que se propõe a transmitir. Por isso, torna-se relevante a participação e avaliação por parte dos sujeitos envolvidos no contexto escolar. Os detalhes sobre os desafios, necessidades e demandas dessas escolas é o que faz com que o estudo seja uma proposta específica para o contexto e as especificidades das Escolas Rurais do Campo.

Os professores e gestores entendem que a comunicação é o que contribuirá para socializar, divulgar práticas, experiências e promover ações que possam colaborar com a formação continuada dos docentes. Conforme escreve Nóvoa (2009, p.30) é no contexto escolar e no diálogo com os demais docentes que "se aprende a profissão. O registro das práticas, a reflexão sobre o trabalho e o exercício da avaliação são elementos centrais para o aperfeiçoamento e a inovação. São estas rotinas que fazem avançar a profissão".

Nesse sentido, a Cartografia Digital se configura enquanto um dispositivo que auxilia e ainda pode continuar contribuindo na comunicação e na socialização das práticas e experiências docentes. Entretanto, para essa comunicação acontecer de modo efetivo, um passo importante é potencializar a oferta de um tempo para conhecer, compreender, manusear as ferramentas e tecnologias disponíveis. Sabendo da excessiva carga-horária dos docentes, bem como demais funções burocráticas, é indispensável que a Cartografia Digital apareça como um importante aliado para que seja possível produzir as práticas e, ao mesmo tempo, compartilhar experiências e vivências nas Escolas Rurais do Campo, em detrimento de mais uma ferramenta que possa vir a aglutinar ainda mais tarefas a serem vencidas ao longo do trabalho pedagógico.

Nas duas escolas pesquisadas, foi possível observar uma proposta de recuperação e superação, envolvendo todos os profissionais da educação, que buscam fazer o seu melhor em prol da formação dos seus alunos e a valorização da comunidade. Neste sentido, foi elaborada uma página direcionada para a formação continuada de professores com vídeos que diferenciam a educação rural e a educação do campo, pois esta foi uma das solicitações dos professores. Com o intuito de facilitar o acesso as leis e diretrizes específicas para a Educação do Campo, foi inserido, na CDERC, um link da Secretaria de Educação do Rio Grande do Sul (SEDUC), que direciona para todas as informações pertinentes ao contexto, bem como um canal de comunicação que pode ser estabelecido com um link do Google Hangouts.

Utilizando o mapeamento das trinta escolas e com base na teoria do rizoma de Deleuze e Guattari (1995), foram 
simbolizadas as ramificações da comunicação, das relações e da formação continuada de professores com representações rizomáticas. Para os autores, uma conexão que "no coração de uma árvore, no oco de uma raiz ou na axila de um galho, um novo rizoma pode se formar. Ou então é um elemento microscópico da árvore raiz, uma radícula, que incita a produção de um rizoma" (Deleuze \& Guattari, 1995, p. 24). Dessa forma, as interligações rizomáticas que para Deleuze e Guattari (1995) desconstituem a ideia de centralização ou hierarquia, possibilitam nesse estudo a produção de ramificações dos saberes, as relações espontâneas e que podem surgir a qualquer momento ao longo de um processo.

O Rizoma "tem formas muito diversas, desde sua extensão superficial ramificada em todos os sentidos até suas concreções em bulbos e tubérculos, [...] é muito diferente da árvore ou da raiz que fixam um ponto, uma ordem" (Deleuze \& Guattari, 1995, p. 16). Essas ramificações serão compreendidas pelas suas interligações entre as Escolas Rurais do Campo. A comunicação e a possibilidade de olhar a realidade amplificada, no desejo de construir uma nova história para essas comunidades, pode ser expandida pela visualidade que a Cartografia Digital constitui, conforme é possível de ser percebido na Figura 4.

Figura 4 - linhas imaginárias representando a comunicação, as relações e a formação continuada de professores entre as Escolas Rurais do Campo.

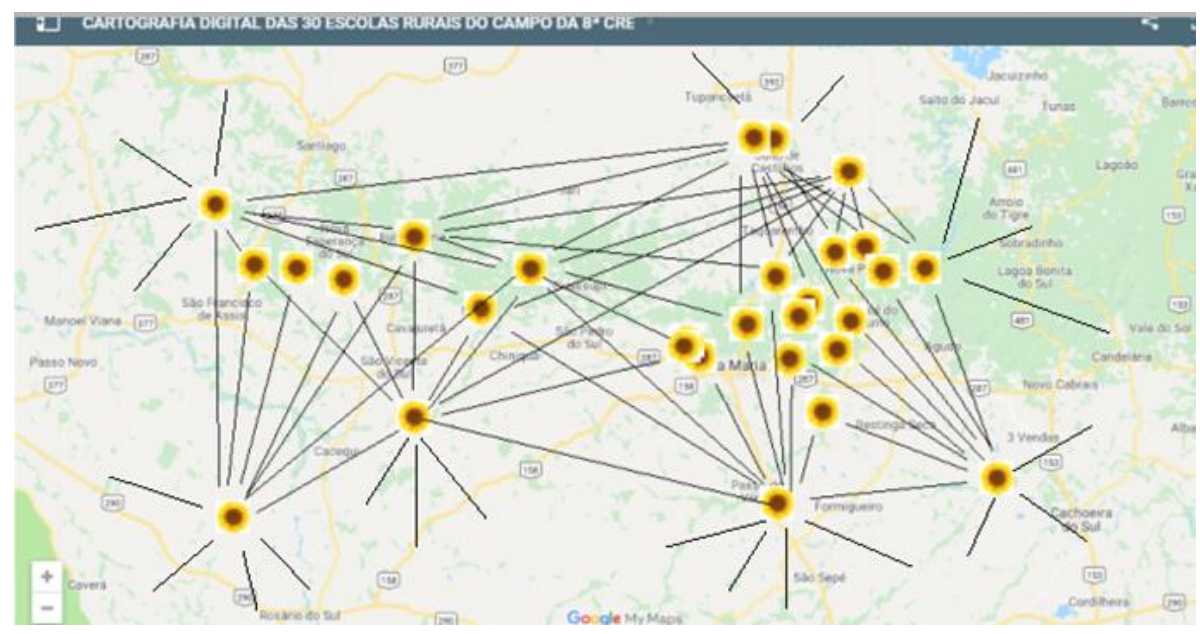

Fonte: Arquivo Autoras.

As interrelações não se limitam apenas entre as trinta escolas, deixam caminhos abertos para que a qualquer momento possam surgir novas relações com outras escolas. Uma "Rede Virtual de Formação" continuada "[...]contexto construído a partir de um complexo cognitivo, potencializado pela acessibilidade às ferramentas das Tecnologias da Informação e Comunicação, tornando-se suporte à inovação profissional, institucional e social” (Maciel, 2006, p. 380).

Essa comunicação poderá criar um elo entre as escolas e a disseminação de ações que reintegram a identidade local. Fator importante, para tentar combater "indicadores sobre o desfavor e a pobreza das colectividades rurais, evidenciando, como nunca antes, a falência dos velhos modelos de crescimento económico" (Amiguinho, 2008, p. 24).

Para contribuir nessa reestruturação institucional, um dos pontos fortes é a participação das famílias, o envolvimento de professores, alunos e comunidade que fortalece a escola. Nessa rede todos colaboram. Essa colaboração pode ser sentida nas expressões dos professores, ao narrar suas experiências e a motivação no trabalho que realizam. É possível observar, que "[...] a diversidade presente nos diferentes modos de ser e constituir-se docente possibilita a produção de um outro conhecimento sobre os professores e sobre a profissão" (Dolwitsch \& Antunes, 2018, p. 1003). Assim, quando os professores e professoras assumem o compromisso social “[...] converge para a construção de princípios, de valores, de inclusão social e cultural e, principalmente, para a importância do sentimento de pertencimento - ao contexto rural, à terra, à agricultura, à comunidade" (Dolwitsch \& Antunes, 2018, p. 1007). 
Isso reforça a importância do sentir-se pertencente ao contexto escolar, pois fortalece o trabalho, o vínculo e as relações, principalmente quando moram na comunidade. Assim,

[...] o lugar não pode ser considerado/entendido isoladamente. O espaço em que vivemos é o resultado da história de nossas vidas. Ao mesmo tempo em que ele é o palco onde se sucedem os fenômenos, ele é também ator/autor, uma vez que oferece condições, põe limites, cria possibilidades" (Callai, 2004, p. 236).

Torna-se necessário transformar técnicas padronizadas de ensinar, para formar cidadãos críticos e reflexivos. Para mudar essa realidade é preciso fortalecer os professores, os quais, conforme Tardif $(2014$, p. 218) tem saberes que "[...] dependem intimamente das condições sociais e históricas nas quais ele exerce seu ofício, e mais concretamente das condições que estruturam seu próprio trabalho num lugar social determinado". Esse fortalecimento se dá quando há união e colaboração na busca constante de estratégias para melhorar o ensino e aprendizagem. Um fator positivo, nas escolas pesquisadas, é o apoio dos gestores no incentivo a projetos para aproximar as famílias da escola:

[...]ao trazer a comunidade para dentro da escola, especialmente, nos eventos organizados em reuniões pedagógicas, valorizar as iniciativas dos professores e outras ações que auxiliam no desenvolvimento de uma educação de qualidade, os gestores demonstraram a sua compreensão sobre a importância de uma gestão escolar democrática e o seu reconhecimento ao trabalho dos professores (Leite e Leão, 2018, p. 77).

Essas ações reforçam, a importância da união, do compartilhamento de ideias e experiências, do trabalho coletivo. Uma mudança de postura, necessária para as famílias contribuírem na formação das crianças,

a cultura tem uma influência determinante nas práticas docentes em alfabetização, uma vez que essas dependem de um conjunto de fatores que são regulados pelos seguintes segmentos: o poder público por meio de políticas educacionais; as famílias dos alunos representantes da sociedade em geral; os próprios docentes com as potencialidades e as fragilidades da sua formação. (Leão, 2009, p. 1).

A cultura vai se moldando com as atitudes dos gestores e das professoras. A aproximação e o apoio das famílias é fundamental para a aprendizagem dos alunos, vem ao encontro da teoria de Imbernón $(2019$, p.1), que o professor não deve “[...] ser um técnico que desenvolve ou implementa inovações prescritas, mas sim um profissional que deve participar ativa e criticamente no processo de inovação e mudança como um agente dinâmico, cultural, social e curricular". Para contribuir com a formação continuada dos professores, a cartografia digital tem um espaço reservado para que as escolas possam divulgar suas ações e que, juntos, possam encontrar soluções para seus desafios.

Essa estruturação passa a ser válida quando os pares se identificam em busca de um mesmo objetivo, visando a competência e desenvolvimento coletivo. Em virtude disso, defendemos a utilização da Cartografia Digital das Escolas Rurais do Campo como elo na comunicação, na socialização de experiências e práticas pedagógicas. Uma potente ferramenta para contribuir com a formação continuada dos professores e na valorização da atuação profissional.

\section{Considerações Finais}

Ao longo da construção da Cartografia Digital, foram identificadas e fortalecidas as potencialidades de cada escola, por meio da pesquisa e da divulgação de suas ações, com vistas a uma reflexão entre escolas, docentes e gestores. O CDERC constituiu-se enquanto palco da formação continuada para professores atuantes nas Escolas Rurais do Campo.

A Cartografia Digital das Escolas Rurais do Campo alarga a possibilidade de comunicação entre as escolas, bem como a troca de saberes e formação continuada dos professores, ampliando as suas visibilidades e, portanto, horizontalizando o acesso às suas características, peculiaridades e especificidades.

Essas novas sensibilidades inauguradas com a construção da Cartografia Digital das Escolas Rurais do Campo 
possibilitam um novo olhar para as instituições de ensino, bem como a escuta e direito de se expressar, compreendendo e respeitando aquilo que chega na medida em que se permite atentar para o território e sua história.

A produção da Cartografia Digital das Escolas Rurais do Campo, tem um significado especial formativo, pois esse estudo proporcionou o conhecimento sobre a realidade das 2 (duas) escolas e contribuiu para a divulgação de boas práticas e interlocuções entre as mesmas e o GEPFICA/UFSM. Diante do trabalho realizado, fica a percepção sobre cartografar como sendo um movimento de autoreconhecimento, não só do território onde estão localizadas essas escolas, mas, tudo o que acontece dentro delas. Cartografar é reconhecer algo que se busca conhecer e pesquisar, detalhadamente, nas dimensões da escrita, escuta, observação, compreensão e representação gráfica. Marcos de uma história, dos sentimentos e dos sonhos que estão presentes em cada contexto.

Ao investigar a realidade dessas comunidades, com a escuta atenta aos costumes, demandas e necessidades dos sujeitos da pesquisa, buscamos cartografar novas formas e possibilidades de reinventar e incentivar a permanência dessas escolas nas suas localidades. Apesar da tecnologia estar, aos poucos, chegando em todas as regiões é preciso utilizá-la não apenas com fins de rede social, mas, ao contrário, como rede de compartilhamento de saberes e, até mesmo, de formação continuada de professores.

Assim, a Cartografia Digital toma o espectro de um elo de comunicação que permite potencializar a formação continuada de professores, principalmente em um contexto que é marcado pela falta de interlocução entre os pares, justamente pelas especificidades do território, das políticas públicas, do acesso à rede de internet, da cultura, e das formas de estabelecer relações com o conhecimento e o cotidiano.

Para isso, neste ano de 2022, estamos iniciando a divulgação da Cartografia Digital, bem como iniciando novos projetos de pesquisas que serão realizadas pelo grupo Gepfica com intuito de ampliar o compartilhamento das práticas, necessidades e demandas das escolas desse contexto. Dessa forma, será posível contribuir com a rede colaborativa e com a formação continuada dos professores e professoras das escolas rurais do campo.

\section{Referências}

Amiguinho, A. (2008). Escola em meio rural: uma escola portadora de futuro? Rev. Educação Santa Maria. 33(1) 11-32. http://www.ufsm.br/ce/revista.

Arroyo, M. G. (1999). A educação básica e o movimento social do campo. In Arroyo, M. G., \& Fernandes, B. M. A educação básica e o movimento social do campo, Cadernos: Por uma educação básica do campo, (pp. 13-42). Ministério do Desenvolvimento Agrário.

Brasil. (2008). Diretrizes para a Educação Básica. Ministério da Educação Conselho Nacional de Educação Câmara de Educação Básica Resolução n ${ }^{\circ}$ 2, de 28 de abril de 2008. http://portal.mec.gov.br/secad/arquivos/pdf/resolucao0208.pdf.

Callai, H. C. (2004) Aprendendo a ler o mundo: a Geografia nos anos iniciais do ensino fundamental. Cad. Cedes, 25, (66), 227-247. http://www.scielo.br/pdf/ccedes/v25n66/a06v2566.pdf.

Carvalho, E. A. de. (2008). Leituras cartográficas e interpretações estatísticas I: geografia / Edilson Alves de Carvalho, Paulo César de Araújo. - Natal, RN: EDUFRN 2008. http://www.ead.uepb.edu.br/va/arquivos/cursos/geografia/leituras_cartograficas/Le_Ca_A01_J_GR_260508.pdf.

Dolwitsch J. B \& Antunes, H. S. (2018). Narrativas (auto)biográficas: percursos formativos de uma alfabetizadora. Revista Brasileira de Pesquisa (Auto)biográfica. Salvador. https://www.revistas.uneb.br/index.php/rbpab/article/view/5606/3547.

Deleuze, G \& Guattari, F. (1995). Mil platôs: capitalismo e esquizofrenia, 1(34) [tradução de Aurélio Guerra e Célia Pinto Costa].

Figueiredo, E. L., \& Silva, N. V. da. (2020). Contribuições da educação do campo para uma formação omnilateral. Research, Society and Development, 9(9), e121996917. https://doi.org/10.33448/rsd-v9i9.6917.

Gelocha, E. A. N., \& Antunes, H. S. (2021). Trajetória da Educação Rural para a concepção social e política da Educação do Campo no Brasil. Research, Society and Development, 10(8), e8010816892. https://doi.org/10.33448/rsd-v10i8.16892

Kolling, J.E., Cerioles, P. R. \& Caldart, R. S. (2002). Educação do campo: identidades e políticas públicas.Brasília: Articulação Nacional por uma Educação do Campo. (Coleção por uma educação do campo, no ${ }^{\circ}$ 4). http://www.forumeja.org.br/ec/files/Vol\% 204 \%20Edu ca \%C3 \%A7\%C3\%A3o\%20B\%C3\%A1sica\%20do\%20Campo.pdf.

Leão, D. O. de. (2009). Vivências culturais nos cenários da alfabetização: formação, saberes e práticas docentes. 109 f. Tese (Doutorado em Educação) Pontifícia Universidade Católica do Rio Grande do Sul, Porto Alegre. http://tede2.pucrs.br/tede2/handle/tede/3606 
Research, Society and Development, v. 11, n. 3, e41711326552, 2022 (CC BY 4.0) | ISSN 2525-3409 | DOI: http://dx.doi.org/10.33448/rsd-v11i3.26552

Maciel, A. M da. R. Verbete: rede virtual de formação. In: Morosini, M. (ed.). Enciclopédia de Pedagogia Universitária: Glossário. 2 . INEP. 380-81.

Medeiros, M. O. de. (2012). Novos olhares, novos significados: a formação de educadores no campo. Tese de doutorado. Universidade de Brasília, Faculdade de Educação. https://repositorio.unb.br/bitstream/10482/12235/1/2012_MariaOsanetteMedeiros.pdf.

Menezes, P. M. L de. \& Fernandes, M. C. (2013). Roteiro de cartografia. Oficina de textos.

Monmonier, M. S. (2002). A Comunicação Cartográfica. In: AUTOR Princípios de Cartografia Básica, vol. 1, cap. 3 da série Princípios de Cartografia.

Nóvoa. A. (2009). Professores Imagens do futuro presente. EDUCA Instituto de Educação Universidade de Lisboa Alameda da Universidade 1649-013 Lisboa |Portugal.

Autor, M. (2019). A cartografia digital das escolas rurais do campo como dispositivo na formação continuada de professores (Dissertação de Mestrado) Universidade Federal de Santa.

Recuero, R. (2012). A conversação em rede: comunicação mediada pelo computador e redes sociais na internet. Sulina.

Santos, Milton. (2006). A Natureza do Espaço: Técnica e Tempo, Razão e Emoção / Milton Santos. (4a ed.), Editora da Universidade de São Paulo. - (Coleção Milton Santos; 1).

Silva, M. L. L. da; \& Leão, D. O. De (2018). A gestão escolar democrática e o princípio de valorização e reconhecimento do trabalho do professor. Regae: Rev. Gest. Aval. Educ. Santa Maria 7(15), 77-90. https://periodicos.ufsm.br/regae/article/view/32901/pdf.

Tardif, M. (2014). Saberes docentes e formação profissional. (16a ed.), Vozes. 